que afirman la complejidad del Guzmán y la necesidad de manejar con sumo cuidado los datos biográficos en relación con la obra.

University of California, Los Angeles.

Carroll B. Johnson

\title{
LOS SUPUESTOS MODELOS DE LAS EMPRESAS DE SAAVEDRA FAJARDO Y SU CARÁCTER ENSAYISTICO
}

La valoración de la obra capital de Diego Saavedra Fajardo, Idea de un principe politico-cristiano representada en cien empresas, ha dado lugar a las más curiosas conclusiones. En principio, aquellos críticos que profundizaron en su estudio están de acuerdo en considerar a las Empresas -en palabras de Vicente García de Diego- superior a "cuantos libros en España y fuera de ella han tratado el mismo tema 1". La contradicción surge cuando se trata de establecer dónde radica el valor. Para unos, siguiendo a José María Ibáñez García, es su originalidad y enorme erudición lo que la hace destacar y ser digna de estudio, pero los mismos críticos lamentan que su estilo sea seco, oscuro... Para otros, García de Diego entre ellos, la obra carece de originalidad ya que es imitación, en. tre otras muchas obras, de los Emblemata politica de Jacobo Bruck Angermunt. Según estos últimos críticos, el verdadero valor radica en el "estilo", pero no llegan a señalar con claridad en qué consiste tal "estilo" 2.

Estoy convencido de que las Empresas constituyen una culminación original -tanto en su estructura y contenido como en su estilo- donde se enlazan las tradiciones de las "divisas", "emblemas", "tratados políticos" y la "ensayística".

1 Diego Saavedra Fajardo, Idea de un principe politico-cristiano representada en cien empresas, ed. de Vicente Garcia de Diego, Madrid, 1958, t. 1, p. xxxiv. Esta opinión sobre las Empresas no sólo es compartida por los hispanistas desde José María Ibáñez García (Saavedra Fajardo. Estudios sobre su vida y sus obras. Murcia, 1884) a John C. Dowling (Diego de Saavedra Fajardo, Boston, 1977), sino que coincide con los juicios de los estudiosos de la emblemática europea en el siglo xvn. Mario Praz se expresa en los siguientes términos: "The most remarkable treatise of political devices for the use of a prince was written by a pious layman, the Spaniard Diego Saavedra Fajardo" (Studies in seventeenth-century imagery, Roma, 1964, p. 191).

2 Una excepción es el libro de John C. Dowling, El pensamiento politico-filosófico de Saavedra Fajardo, Murcia, 1957, en cuyo análisis del estilo de las Empresas da ya énfasis a los rasgos que precisamente caracterizan lo ensayístico de la obra. La empresa -dice Dowling- "permitió al escritor hacer la división interna por medio de conceptos aislados en vez de seguir el desarrollo sistemático de su materia... El pensamiento no sigue una línea continua. Recibe su impulso inicial de un motivo concreto aislado. La línea se rompe o desaparece en el esfuerzo de dar mayor sentido de vivacidad... El autor puede dejar sin desarrollar alguna línea de pensamiento, lo cual le preocupaba poco, porque lo importante era presentar artísticamente sus ideas" (p. 63). 
Veamos primero su estructura y contenido, para después estudiar algunos aspectos de su estilo. Como punto de partida nos serviremos de la siguiente gráfica:

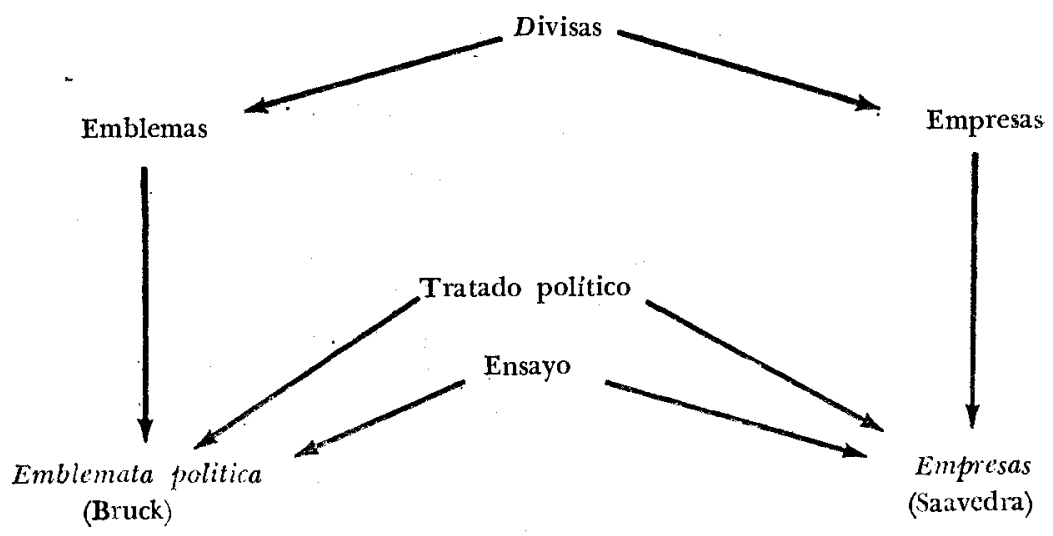

Es hoy dia común entender como sinónimos los términos "divisas", "emblemas" y "empresas" - así los usa García de Diego en su edición de Idea de un principe politico-cristiano. Durante los siglos xvI y xvn, sin embargo, existía, sobre todo en Italia y en España, una clara distinción entre dichos términos, a cuyo propósito se escribieron numerosos tratados donde se intentaba fijar las caracteristicas de lo que entonces se consideró un nuevo género literario ${ }^{3}$. Las divisas, muy en boga en los siglos XIV y xv, son en realidad una supervivencia medieval adaptada a la ideología del barroco. En la época medieval formaban parte de la heráldica, pero con el Renacimiento salieron del amparo de los caballeros para pasar a los hombres de letras, en conexión con la publicación en Italia, en 1419, de los Hieroglyphica de Horapollo. Las divisas consistían en un grabado alegórico en el que no se podía representar la figura humana en su apariencia contemporánea, y un mote breve en lengua distinta a la del autor de la divisa, generalmente en latín. Con la publicación de Emblematum Liber (Augsburg, 1531), de Alciato, el nuevo "género literario" comenzó a difundirse en Europa. Con Alciato comienza igualmente una diversificación, y sus emblemas, aunque se originan en las divisas, son muy distintos a éstas. Una somera comparación de ambos ante los cuatro principios básicos establecidos por Giovio en 1555,

3 De especial interés para nosotros es la obra de Paolo Giovio, Dialogo delle Imprese militari e amorose (1555), que Alonso de Ulloa tradujo al español con el titulo: Diálogo de las empresas militares, y amorosas (León de Francia, en casa de Guillielmo Roville, 1562). Esta edición española es sin duda más completa que la italiana y la francesa, pues Ulloa incluye "un razonamiento a esse propósito, del magnifico señor Ludovico Domeniqui" (comentador italiano), y añade "a esto las empresas heroicas, y morales, del señor Gabriel Symeon" (traductor al francés). Necesarios para la verdadera comprensión de lo que el "género literario" de las empresas representó en el siglo xvi y xuII, son los tratados de Scipione Borgagli, Delle Imprese, 1578; y el de Ercole Tasso, Della realtà e perfezione delle imprese, 1612. 
servirá para determinar sus características: 1) En la divisa debía haber una justa proporción entre el cuerpo (grabado) y el alma (mote). En los emblemas, además del mote se incluían varios versos explicativos al modo de un epigrama. 2) Su significado no debía ser tan claro que cualquiera pudiera comprenderlo, ni tan oscuro que se necesitara ser adivino. En los emblemas esta dificultad desaparecía, pues los versos que se añadían al pie del grabado servían para explicarlo. 3) La figura humana no se debía representar y de hacerlo debería ser sólo en función alegórica; Alciato no hizo tal distinción y en sus emblemas aparece la figura humana cuando su pensamiento así lo requiere. 4) El mote debe ser en lengua distinta a la del autor de la divisa; los autores españoles mezclaron el latín y el español sin regla fija. Los emblemas de Alciato, además de las diferencias anotadas, divergían de las divisas en su función y propósito. Las divisas hacían referencia a hechos pasados, los emblemas contenían una enseñanza moral para aplicar al futuro ${ }^{4}$. Paralelamente a los emblemas aparecieron las empresas que venían a representar la función de los emblemas, pero siguiendo las ya señaladas "reglas académicas" de las divisas, y concentrando su contenido a un asunto particular 5 .

Si partiendo de las consideraciones precedentes analizamos las $\mathbf{E}$ presas de Saavedra Fajardo y las opiniones de la crítica sobre ellas, en seguida se pone de manifiesto la falta de correspondencia entre éstas y la obra, y la confusión en el uso de los términos emblema y empresa. El origen es siempre el mismo: el amplio estudio que a modo de introducción coloca Vicente García de Diego en su edición de las Empresas (Clás. Cast., 1927). En efecto, García de Diego no establece distinción entre empresa y emblema; y propone como antecedente de la obra a Saavedra Fajardo, los Emblemata politica (1618), de Jacobo Bruck Angermunt: "Tenemos que admitir -dice-, después de la comparación de las Empresas con esta obra, que Saavedra la conoció, y que fue este libro el modelo en que nuestro autor se inspiró al resolverse a escribir el tratado de educación del príncipe ".".

4 Información más completa se encontrará en el libro de MARIo Praz, cit. supra, nota 1 .

5 Alonso López Pinciano en su obra Philosophia antigua poética, ed. Alfredo Carballo Picazo, Madrid, 1973, señala las diferencias en los siguientes términos: "Solamente se ata al autor de la Emblema a poner ánima y cuerpo en ella ... átase también la Emblema a no tratar cosa particular, porque en tal caso sería Empresa, la qual dista de aquélla en poco más que lo dicho, digo, en que la Empresa mira a respecto particular siempre" (I, p. 296). "Las Empresas buenas y perfectas ... no han de tener figura de hombres, y aún que el mote no sea muy largo" (I, p. 298).

6 Pról. cit., p. xxix. Basan sus opiniones en García, entre otros, los siguientes críticos: JuAn Luis Alborg, que señala: "Parece seguro que Saavedra conoció esta obra y aun que debió servirle de inspiración para su propósito general; además, muchos de los emblemas del alemán han sido imitados por Saavedra, y algunos -dice García de Diego- 'estrictamente copiados'" (Historia de la literatura española, Madrid, 1967 , t. 2, p. 883) . ANGel GonzÁlez PALencia dice: "Saavedra aplica la representación de empresas a la teoría de educación de Príncipes, siguiendo de cerca a Jacobo Bruck Angermunt en sus Emblemata politica (1618), dedicados al Emperador Matías. También demuestra García de Diego que Saavedra conoció este libro y lo utilizó 
En principio, lo único que ambas obras poseen en común es el tema general: la educación del príncipe. Pero aun así resulta que el libro de Bruck no es nada más que uno de los varios que se publicaron antes de la aparición de las Empresas ${ }^{7}$. Por otra parte, el libro de Bruck, como su título indica, es una colección de emblemas (54 en total); el de Saavedra Fajardo lo es de empresas. Los emblemas de Bruck, siguiendo en ellos la tradición emblemática, constan de un mote, un grabado y unos versos explicativos; las empresas de Saavedra sólo poseen el mote y el grabado. Bruck representa la figura humana en la mayoría de sus emblemas -en varios de ellos en primer plano-; Saavedra, consciente de su arte, evita su uso, no sin que a veces sienta que las reglas se lo prohiban, como sucede en la empresa 20, donde después de señalar un ejemplo propicio indica: "Con él pudiéramos significar también (si permitieran figuras humanas las empresas) al que nace para ser rey" (I, p. 183).

Es cierto que tanto Bruck como Saavedra incluyen unas reflexiones en prosa a continuación de cada emblema o empresa, pero esto también era práctica general en la época. En España, por ejemplo, Diego López lo hace en su edición del libro de Alciato, Declaración magistral sobre los emblemas (Nájera, 1615). Pero, incluso aquí hay una diferencia básica entre Saavedra y Bruck. La extensión de los comentarios de Bruck, sorprendentemente sistemática, oscila entre dos páginas y media o tres; en Saavedra no existe regla y la extensión parece depender más que del tema, de la inspiración del momento en que la escribió; así se explica que, por ejemplo, la empresa 77 tenga sólo dos páginas y que la 50 tenga 31 .

Si de estos detalles de conjunto pasamos ahora a los particulares, de nuevo encontramos que las afirmaciones de García de Diego no tienen fundamento sólido y que a lo máximo representan una interpretación. García de Diego dice: "Un breve análisis demostrará cómo en unos emblemas se ha inspirado o ha podido inspirarse Saavedra, y cómo otros han sido estrictamente copiados" (I, p. xxx), y encuentra afiliación directa en las empresas 11, 12, 44 y 70. Esta opinión de García de Diego, formulada en 1927, podría haberse superado hace tiempo si los estudiosos de la obra de Saavedra hubieran tratado de comprobar sus afirma-

alguna vez como modelo" (Del "Lazarillo" a Quevedo, Madrid, 1946, p. 251). CÉSAR Silıó Cortés en su libro Maquiavelo y su tiempo (Madrid, 1946) no sólo sigue a García de Diego, sino que en lo referente a los modelos de Saavedra en las Empresas lo cita extensamente en las páginas 118-119. En fin, Francisco Ayala en El pensamiento vivo de Saavedra Fajardo (Buenos Aires, 1945) lleva al extremo la posición de García de Diego: Saavedra es, dice, "un escritor que sigue modelos y métodos de composición literaria habituales, hasta el punto de que no hay obra suya que no pueda valer como un ejemplo más - $y$, por supuesto, muy notable- de algún género cultivado antes de él hasta el cansancio" (p. 19).

7 Entre los libros de emblemas dedicados a un príncipe que precedieron a la publicación de las Empresas destacan: Giulio Cesare Capaccio, Principe tratto dagli Emblemi dell'Alciato (Venecia, 1620), dedicado a Federico II de Urbino; Justus Reifenberg, Emblemata politica (Amsterdam, 1632); Marcus Zuerius Boxhornius, Emblemata politica (Amsterdam, 1635). Para mayor información véase el libro de Mario Praz citado anteriormente. 
SAAvedra, núm. 11

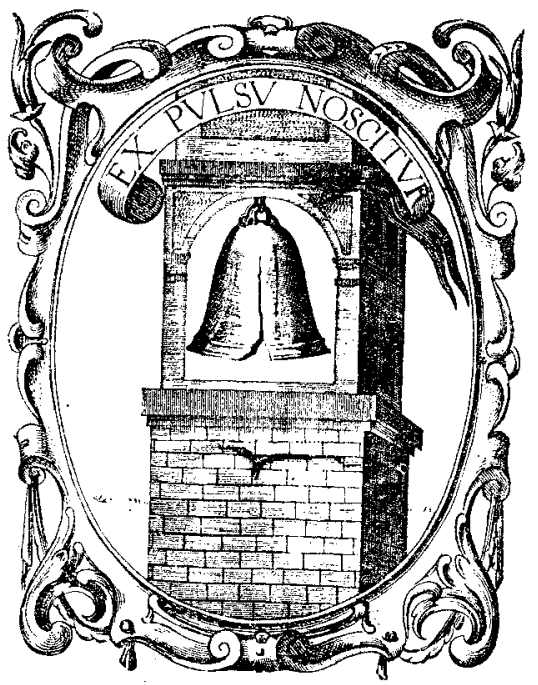

Son las palabras el semblante del ánimo; por ellas se ve si el juicio es entero o quebrado. Para significar esto se buscó otro cuerpo más noble y proporcionado, como es la campana, símbolo del príncipe, ... Así el príncipe es un reloj universal de sus estados, los cuales penden del movimiento de sus palabras; con ellas o gana o pierde el crédito, porque todos procuran conocer por lo que dice su ingenio, su condición e inclinaciones.
EMBLEMA XXV.

Usus BEAT.

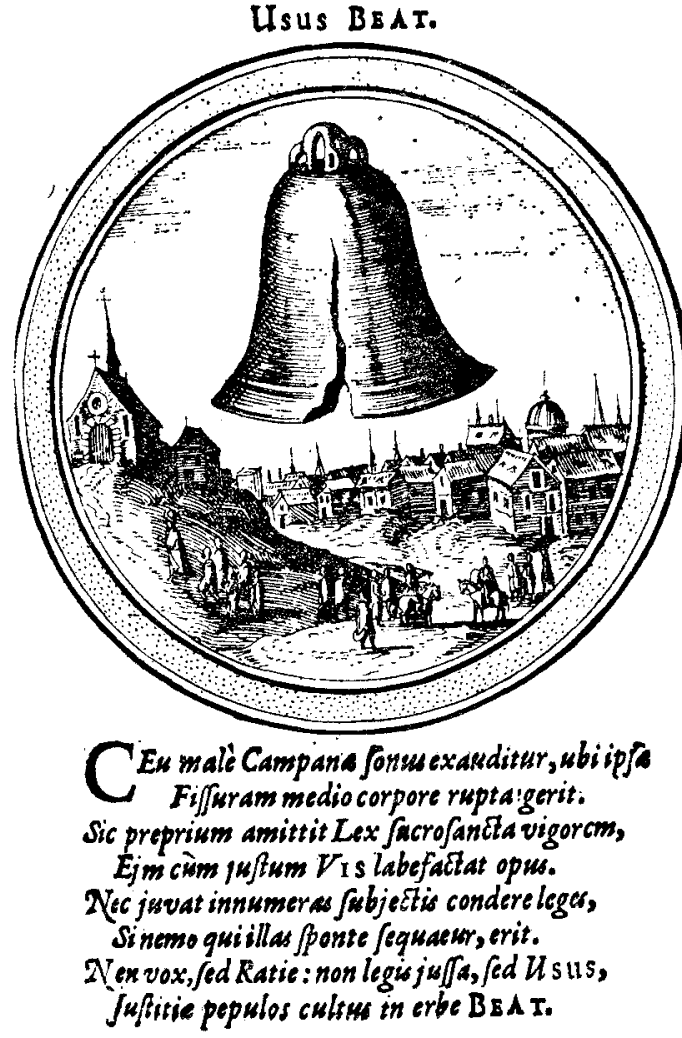

ciones antes de hacer uso de ellas. Analicemos ahora brevemente cada uno de estos casos.

La empresa 11, que según García de Diego corresponde al emblema 25 de Bruck, representa una campana en una torre; no existe torre en Bruck, pero sin duda el motivo central del grabado es el mismo, si salvamos las diferencias de detalle que ya por definición existen entre el emblema y la empresa ${ }^{8}$. Establecida la semejanza, conviene señalar que el símbolo, aun siendo raro, ya lo había utilizado en un sentido similar

8 "En la Empresa no ha de auer cosa que no signifique, y en las Emblemas puede auer ornato y compañía, y es necesario suppuesto que siempre se pintan como en quadros, y por lo menos se acompañan de tierra y cielo, y assi puede auer arboles y plantas y lexos mas de manera que se conozca lo que es principal y lo que es acessorio y ornato" (Orozco y Covarrubias, op. cit., citado por KarL Ludwig Selig, "La teoria dell'emblema in Ispagna: i testi fondamentali", Convivium, 23 (1955), p. 414. En nuestro ejemplo, en el emblema, la campana se encuentra suspendida en el aire sobre una ciudad cuidadosamente representada y en la que se divisan numerosas personas. 
Figura II

SAAVEDRA, núm. 12

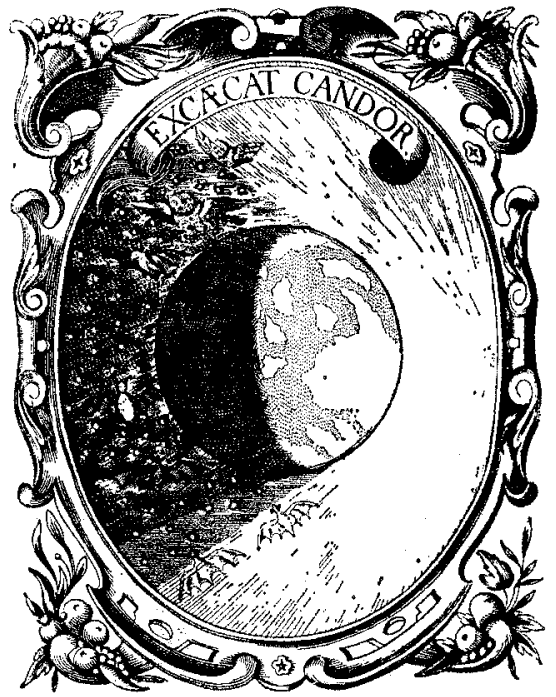

El que miente no puede resistir a los rayos de la verdad, significada por el sol, así en ser uno, como en que deshace las tinieblas y ahuyenta las sombras, dando a las cosas sus verdaderas luces y colores; como se representa en esta empresa, donde, al paso que se va descubriendo por los horizontes el sol, se va retirando la noche, y se recogen a lo obscuro de los troncos las aves nocturnas.
EMbiema. XLI. INTUTA QuA INDECORA.

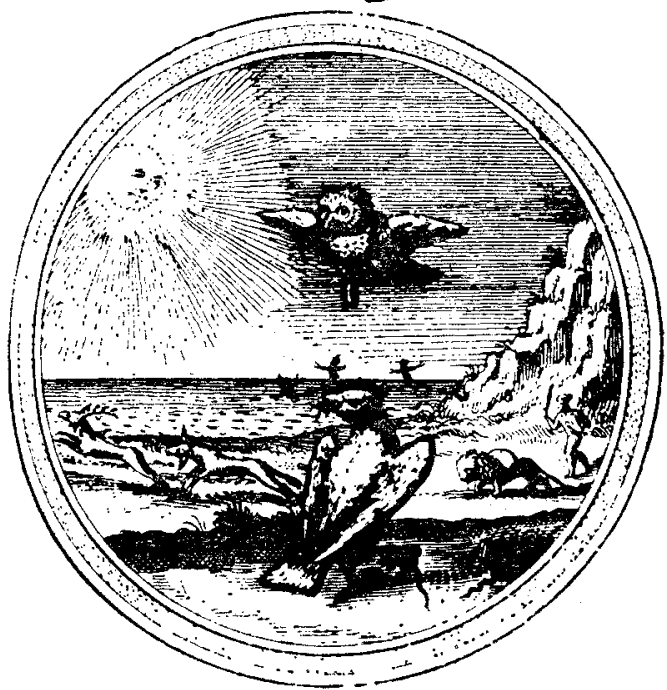

Nothis avis non est ad Solisttndere lomor: Nen aquila muf sess ungue ferire lever. Sors, Virtus, Natura Ducum contraria vilge cit. His proprios fines tranfilyffe nocet. 2lec fas privato, mores effingere regum: Hes vulgare aliguid nec Japuiffe dectet. Simma petant fumme gener of o in corpore mentes: Plebs bumiles humilis guerat o ornot opes.

Theodorus Beza en su Emblemata (Génova, 1580), y que las proyecciones que se hacen a partir del gráfico son distintas en ambos casos: el correcto uso de las leyes en Bruck; la prudencia que el príncipe debe tener en el uso de la palabra en Saavedra (ver fig. I). La empresa 12 se supone imitación del emblema 41 , pero aquí las semejanzas, si las hay, son tan mínimas, que Henkel y Schöne las clasifican en su Emblemata bajo distintas categorías: la empresa en la categoría I "Makrokosmos", y el emblema en la IV "Tierwelt/Tiere der Luft" 9 (ver fig. II) . La empresa 44, se dice, proviene del emblema 32 (García de Diego, por error, hace referencia al emblema 31). En ambos casos los grabados representan una culebra, y si bien la idea general que tratan de representar es la misma, lo hacen desde puntos de vista diferentes. Los mismos grabados, de acuerdo con sus respectivas aproximaciones, contienen una diferencia básica: en la empresa la culebra se enrosca en unas matas, de modo

9 Emblemata. Handbuch zur Sinnbildkunst des xvi. und xvii. Jahrhunderts, ed. de Arthur Henkel y Albrecht Schöne, Stuttgart, 1967. 
FIgURA III

SAAVEDRA, núm. 44

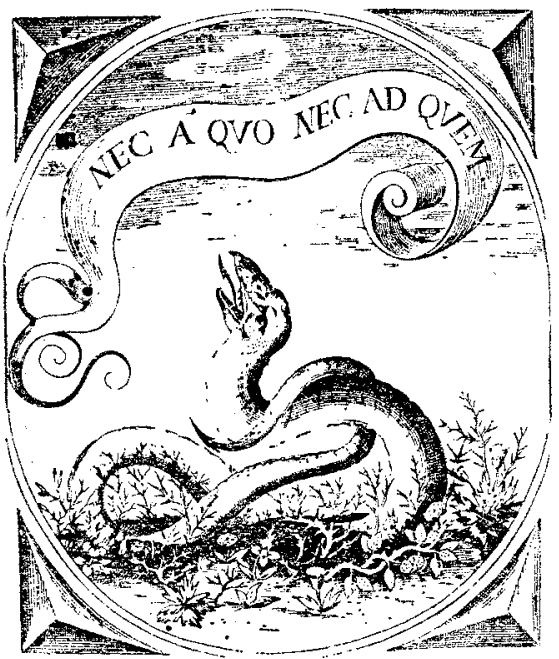

Dudoso es el curso de la culebra, torciéndose a una parte y otra con tal incertidumbre, que aun su mismo cuerpo no sabe por dónde le ha de llevar la cabeza; señala el movimiento a una parte, y le hace a la contraria, sin que dejen huellas sus pasos ni se conozca la intención de su viaje. Asf ocultos han de ser los consejos y designios de los príncipes. Nadie ha de alcanzar a dónde van encaminados, procurando imitar a aquel gran Gobernador de lo criado, cuyos pasos no hay quien pueda entender.
EMbLema. X XXII. Nunguas Sat Cauts.

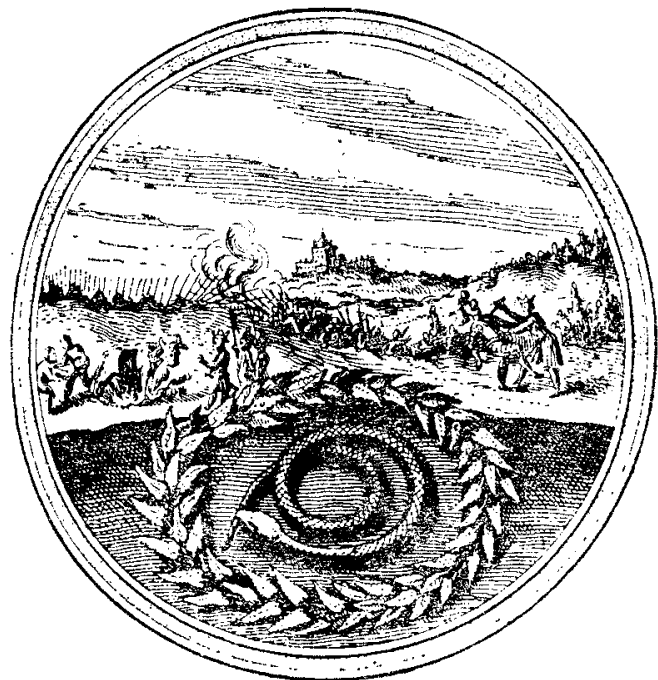

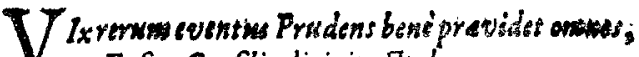
Et fua Comflio dirigit atta bono.

Subdeline interdum quin bec perverteris Errar: Ac fors pravijas fregerie arte operas:

NuxeuAM SAT CauTE' faciendaperegeris: ipfs Cantio fit major grian adbibenda ré.

Frase qnoniam faclis Comes ad/Rat, Cerporiat ambra. Gonfliy astarem frats pressos is ipfa malio.

que la cola no sabe dónde está la cabeza; en el emblema la culebra se encuentra enroscada en forma circular y la cabeza está mordiendo la cola (ver fig. III). Finalmente, con relación a la empresa 70 dice García de Diego: "En un emblema tan singularmente raro como el último del libro de Bruck [número 54], un tronco de un árbol abrazado por una corona real que se rompe al henderse el árbol, y que constituye la empresa 70 de Saavedra, no es posible ver, ni aun apurando todas las sutilezas, sino una pura copia" (I, p. xxxii). De nuevo aquí la semejanza es más aparente que real. Primeramente, los grabados no son del todo exactos: en la empresa, el árbol es joven y vigoroso; causan la hendiduras dos brazos semejantes que tiran de las ramas del árbol en direcciones opuestas. En el emblema, por el contrario, se representa a un viejo roble que, decrépito, se abre. Saavedra quiere con ello indicar que la división destruye a la monarquía; Bruck señala que la degeneración en las leyes, al igual que el viejo roble se abre por medio, deshace a la monarquía (ver fig. IV). 
SAAVEDRA, núm. 70

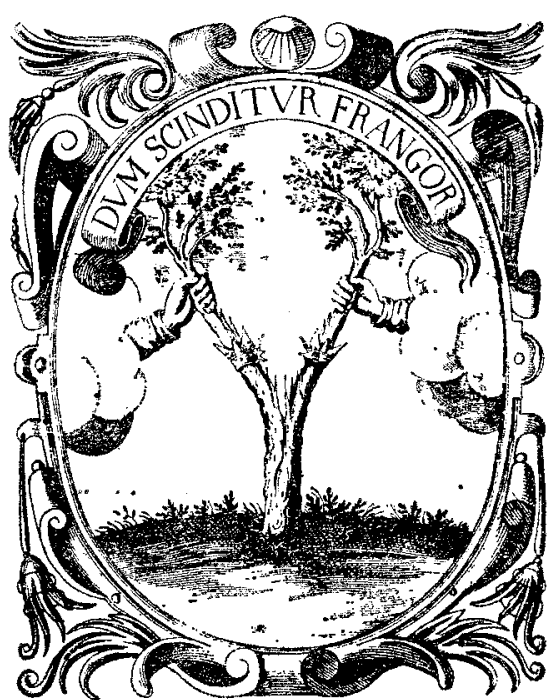

Uno es el cuerpo de la República, y una a de ser el alma, que la gobierna. ... Esta empresa lo representa en el árbol coronado, que significa el Reyno, de quien si tiraren dos manos, aunque sean animadas cle una misma sangre, le desgajarán, y quedará rota, y inútil la Corona, ...
Emrlema. LIV. Sic ContBRit Aitas.

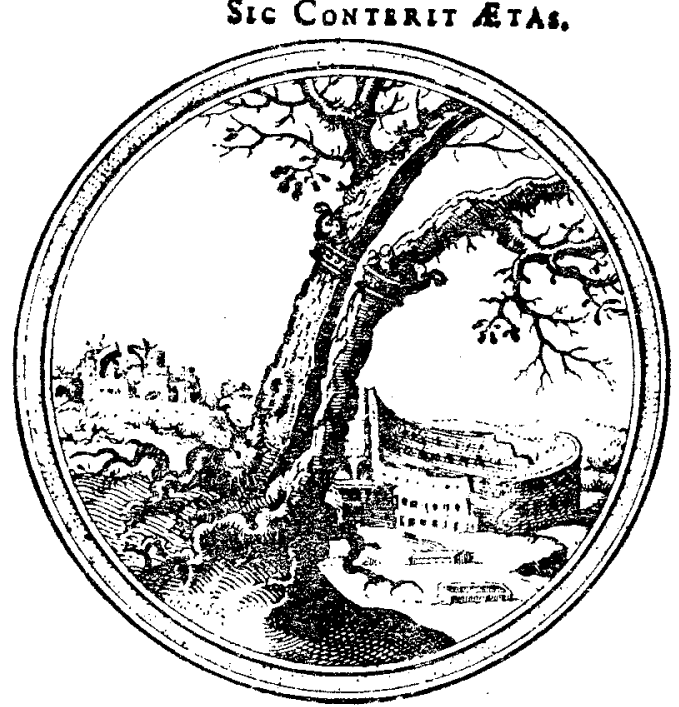

(Rtu regnorum, progrefjus of wltima finis, A fulo pendent bec moderantc $D_{\mathrm{E}} \mathrm{O}_{\text {. }}$. Qua quantum $q_{s}$ dis bene firmâ legeregantur: Attamen bec tandem certa ruina manet. Cernis ut annole jam fumma cacumine quercu Arent, \& medso corpore rupta ruit!

Het immota guidem guàm-pluresforuit annos. Sf terre inelinans, nunc peritura cadit.

Antes de valorar excesivamente los resultados de estas observaciones, es oportuno recordar aquí en qué consistía la originalidad en la tradición emblemática. Juan de Horozco y Covarrubias dice al respecto en su Emblemas morales (Segovia, 1589): "Para Emblema no importa sea propia o sea ajena, porque no se mira sino a lo que enseña" ${ }^{10}$. Es decir, se buscaba no tanto el grabado cuanto el uso que de él se hacía. $Y$ es precisamente en este sentido que la obra de Saavedra Fajardo representa una culminación original. En efecto, en las Empresas se une lo mejor de la tradición de las divisas y emblemas con el propósito de los tratados sobre la educación del príncipe. Pero Saavedra, en su personalismo, se aleja de la sistematización del tratado para escribir una colección de ensayos. Bruck, a pesar del carácter personal de su obra, no consigue superar lo metódico del tratado. Por otra parte, el estilo de ambos libros es igualmente diverso: Bruck prefiere el período ampuloso a imitación de Cicerón, Saavedra el conciso de Tácito. 
El estilo de las Empresas ha sido ya estudiado en numerosas ocasiones y, sobre todo desde García de Diego, justamente ponderado. Por ello, más que un estudio detallado, lo que me propongo ahora es destacar algunos aspectos relegados por la crítica, al mismo tiempo que establezco el carácter ensayístico de la obra.

Al hablar del contenido de las Empresas, se ha hecho referencia una y otra vez a los innumerables tratados políticos que precedieron a la obra de Saavedra, si bien siempre limitándose a una tediosa enumeración de autores, títulos y fechas, sin que en realidad se pasara al análisis comparado de los mismos. Vamos a cotejar aquí brevemente la obra de Pedro de Rivadeneira, considerada insistentemente como uno de los posibles modelos de Saavedra, y que, por representar un desarrollo, según mi opinión, opuesto al de las Empresas, servirá mejor para demostrar el carácter ensayístico de éstas. El titulo completo del libro de Rivadeneira es Tratado de la religión y virtudes que debe tener el principe cristiano para gobernar y conservar sus estados, contra lo que Nicolás Maquiavelo y los politicos deste tiempo enseñan. Rivadeneira considera a su obra un "tratado", y, en efecto, lo es, y por ello su exposición es sistemática. Saavedra, por el contrario, titula a la suya Idea de un príncipe..., con lo que hace clara referencia al carácter reflexivo y asistemático de la misma (además de su afiliación platónica). Es más, el final del título, "representada en cien empresas", refuerza esta posición, ya que si en la primera edición se podía interpretar literalmente, pues efectivamente constaba de cien empresas, en las sucesivas añadió el autor una más sin modificar el título, con lo que cien se convierte ahora también en una expresión para indicar muchas. Rivadeneira escribe un "tratado de la religión y virtudes que debe tener el príncipe cristiano", donde lo de "príncipe" queda subordinado a lo de "cristiano". El carácter idealista se acentúa aún más, en las últimas palabras del título, "contra lo que Nicolás Maquiavelo y los políticos deste tiempo enseñan". Claro está, el término "político" significa aquí seguidor de Maquiavelo, si bien para Rivadeneira lo era cualquiera que pretendiera separar la religión del arte de gobernar. En realidad, los tratados políticos desde mediados del siglo xvi y durante el siglo xvn pueden reunirse, según su aproximación filosófica, en dos grandes grupos: aquellos seguidores más o menos moderados de Maquiavelo, y los que partiendo de las doctrinas contrarreformistas se le oponian decididamente. A este segundo grupo pertenece Rivadeneira y por ello escribe un "tratado de la religión y virtudes" del "príncipe cristiano" dirigido contra "los políticos", Saavedra está más preocupado con la realidad práctica y así escribe sobre un "príncipe político", pero consciente de la connotación negativa que la palabra poseía en su tiempo y para reflejar sus fuertes convicciones morales, su príncipe es "político-cristiano" 11. De cste modo, las Empresas representan un puente de comunicación entre los que con excesivo prag-

11 Pedro Barbosa Homen nos da testimonio del cambio de significado del término "político" en su obra, Discursos de la juridica y verdadera razón de estado... contra Maquiavelo y Bodino y los demis politicos de nuestro tiempo sus secuaces, Coimbra, 1626. En el "Prefacio general" dice que la palabra politico, al igual que 
matismo, como Maquiavelo, subordinaban la religión a la razón de estado, y los que con un idealismo teórico desmesurado, como Rivadeneira o el Quevedo de Politica de Dios, gobierno de Cristo, anteponían la religión a la razón de estado.

Las diferencias entre ambas obras se harían más profundas si ahora cotejáramos los textos, pero bástenos con lo ya indicado para demostrar la necesidad que hay de analizar las Empresas en su contexto y no a la luz de las posibles semejanzas externas con otras obras de su época. Parte de la confusión proviene, sin duda, de haber considerado a las Empresas como un tratado sobre la educación de los príncipes. De ahí que los estudiosos de la obra se negaran, por ejemplo, a aceptar la afirmación de Saavedra Fajardo cuando dice: "He procurado que sea nueva la invención" (I, p. 9). Naturalmente, Saavedra sabía que el contenido de sus empresas no era nuevo; la novedad estaba en la interpretación, en su personal replanteamiento del problema, en la actualización del pasado con su experiencia del presente y, en una palabra, en haber escrito una colección de ensayos sobre el tema ${ }^{12}$. Saavedra escribe las Empresas en su edad madura no en busca de gloria, sino porque sentía la necesidad de comunicar sus pensamientos, y quizás en el deseo de replantearse problemas tan fundamentales en un momento en el que la caída de España era ya inminente, y cuya precipitación se debía precisamente a la forma de gobierno de sus reyes. Por ello escribe para que "no se perdiesen conmigo las experiencias adquiridas en treinta y cuatro años que, después de cinco en los estudios de la Universidad de Salamanca, he empleado en las cortes más principales de Europa, siempre ocupado en los negocios públicos" (I, p. 8). No domina en las Empresas, el carácter didáctico, sino el reflexivo, y por ello sus ensayos carecen de método, de sistema; compuso su obra, dice, "escribiendo en las posadas lo que había discurrido entre mí por el camino" (I, p. T). Como ensayista, para él no sólo son importantes las ideas, sino la forma artística en que éstas deben de ser representadas: "Con estudio particular he procurado que el estilo sea levantado sin afectación, y breve sin oscuridad" (I, p. 10). En la tradición ensayística, si hubiéramos de establecer relaciones, diríamos que el estilo de los ensayos de Saavedra está más próximo a Bacon que a Montaigne, pero manteniendo en todo momento un sello saavedriano que lo hace peculiar. La prosa de la Empresas es aforística, de período breve, muy cercana al estilo de Tácito, cuya obra cita Saavedra repetidamente en sus ensayos. Tales características requieren que su lectura sea lenta y que cada empresa sea considerada como una unidad independiente.

Como ensayista, Saavedra recoge la tradición de su época, y valiéndose de aquello que era patrimonio común lo reelabora en una nueva interpretación basada en sus experiencias personales. Tal es lo nuevo en su obra, y no los "materiales" con los que desarrolló sus ensayos, pues él mismo dice que se ha "valido de ejemplos antiguos y modernos" (I,

sucedió con hereje, había perdido su significado original para pasar a designar a los seguidores de Maquiavelo.

12 John C. Dowling en su libro Diego de Saavedra Fajardo, traduce al inglés -con mucho acierto- la palabra "empresa" por el término "essy". 
p. 12). Aún más, en ocasiones, por decoro, disfraza las referencias concretas a su momento, buscándoles origen clásico ${ }^{13}$. Son, pues, las Empresas no una imitación de innumerables fuentes, como hasta aquí ha dicho la crítica, sino una culminación en la tradición literaria del barroco, y Saavedra es el más genuino representante del ensayo filosófico español del siglo xvn ${ }^{14}$.

The University of Georgia, Athens.

José Luis Gómez Marrínez

\section{LA ẼTICA DE MACHADO}

Antonio Machado, aquel hombre, en el buen sentido de la palabra, bueno, según se definiera él mismo en célebre ocasión, sorprende por el acendrado sentido ético que a lo largo de toda su vida manifiesta en verso y prosa. Éste es acaso uno de los secretos de su inmensa popularidad en el mundo de hoy, al siglo de su nacimiento y a los 40 años aproximadamente de su muerte. En una sociedad moralmente desquiciada, como es la española de hoy, la lectura y relectura de Machado reconforta; es una esperanza y casi una promesa de regeneración ética. El país que ha sido capaz de producir un Antonio Machado no puede perderse definitivamente en el fango de la ruindad, de la envidia y del abuso. Quizá lo que más ganemos o hayamos ganado en estos años con ia frecuentación de Machado sea una confrontación decidida con nuestra propia desesperación. Creo que estas nociones son del dominio común, pero también que nunca se ha tratado de sistematizar las referencias, o mejor dicho, las manifestaciones machadianas de su propia intimidad ética ${ }^{1}$.

Ya en las primeras poesías, las escritas al filo del 900 , encontramos adjetivos pesimistas y dolientes (amarga tierra), suficientemente destacadas por la critica; expresiones que pertenecen desde luego al horizonte lírico del Modernismo, pero no por ello hay que olvidar que esos adjetivos se dan en un momento inicial -y también jayl ulterior- de Anto.

13 En la empresa VI hay un excelente ejemplo al particular. Saavedra está hablando sobre la poesía y la dedicación del rey a ella y dice: "No parece que conviene al príncipe, porque su dulzura suspende mucho las acciones del ánimo, y, enamorado de sus conceptos el entendimiento, como de su canto el ruiseñor, no sabe dejar de pensar en ellos, y se afila tanto con la sutileza de la poesía, que después se em. bota y tuerce en lo duro y áspero del gobierno; y, no hallando en él aquella delecta. ción que en los versos, le desprecia y aborrece y le deja en manos de otro" (I, p. 66). En una nota al margen de la página dice Saavedra que proviene de Aristóteles, pero ¿no pensarían así sin necesidad de conocer a Aristóteles, la mayoría de los funciona. rios conscientes del reinado de Felipe IV?

14 Un resumen de este estudio, bajo el título de "Reflexiones ante las Empresas de Saavedra Fajardo", fue presentado como ponencia en Toronto (agosto de 1977), en el VI Congreso de la Asociación Internacional de Hispanistas.

1 Cf., sin embargo, Geoffrey RibBans: Antonio Machado (1875.1939). Poetry and integrity, London, 1975. 